\title{
Desigualdad social y étnico-racial frente a la covid-19 en Estados Unidos
}

\author{
Social and ethnic-racial inequality \\ under covid-19 in the United States
}

Alejandro I. Canales*

ISSN IMPRESO 1870-7599 | ISSN RED CÓMPUTO 2448-7783 | 129-145

Dídimo Castillo Fernández**

RECIBIDO 15/10/20 | ACEPTADO 5/11/20

\begin{abstract}
Resumen. En Estados Unidos, la pandemia por covid-19 tiene un claro componente de clase y étnico-racial. Sabemos que el virus puede contagiar a cualquier individuo. Sin embargo, también sabemos que la probabilidad de ser contagiado, y los efectos que ese contagio pueden tener en la salud y muerte de la persona varían sustancialmente según condiciones sociales, políticas, demográficas y económicas. Considerando el contexto de racialización de las desigualdades sociales en Estados Unidos, en este artículo analizamos la vulnerabilidad de los migrantes y minorías étnicoraciales frente a la pandemia, desde dos de sus manifestaciones. Por un lado, a partir de la desigualdad social y étnico-demográfica frente a los impactos de la pandemia en las condiciones de salud, enfermedad y muerte de las poblaciones; y, por otro lado, los impactos que la crisis económica ha provocado en la situación laboral y ocupacional de los colectivos migrantes en Estados Unidos.
\end{abstract}

Palabras clave: desigualdad social, racialización, covid-19, migración, empleo.

\begin{abstract}
In the United States, the covid-19 pandemic has a clear class and ethno-racial component. We know that the virus can spread to any person; however, we also know that the probability of catching the virus, and the effects that this illness can have on the health and morbidity, varies substantially according to the population's social, political, demographic and economic conditions. Taking into account the context of racialization of social inequalities in the United States, this article analyzes the vulnerability of migrants and ethno-racial minorities during the pandemic, considering two of its characteristics. One on hand, the social and ethno-demographic inequality with regard to the effects of the pandemic on health, illness and death among those populations; and on the other, the effects brought on by the economic crisis in terms of the labor and occupational realities of migrants in the United States.
\end{abstract}

Keywords: social inequality, racialization, covid-19, migration, employment.

${ }^{*}$ Chileno. Profesor investigador, Universidad de Guadalajara. Correo-e: acanales60@gmail.com

${ }^{* \star}$ Mexicano. Profesor investigador, Universidad Autónoma del Estado de México. Correo-e: didimog9 @ prodigy.net.mx 


\section{Introducción}

Estados Unidos, en un tiempo relativamente más corto y con consecuencias sociales mayores que en sus homólogos europeos y asiáticos, se convirtió en el país más afectado por la pandemia a escala mundial. Más allá de que las estrategias de contención, primero, y mitigación, después — si es que las hubo-, hayan fracasado, los resultados son los altos niveles de contagio y muertes experimentadas en todos los sectores de la población, pero en particular entre los más vulnerables: las comunidades afroamericanas y latinas, laboralmente más expuestas a los contagios, con menores recursos para mantener las medidas de cuidado y confinamiento, así como sus limitadas posibilidades de acceso a los sistemas de seguridad social y de atención a la salud.

De manera paulatina la pandemia ha vulnerado la seguridad de los Estados en distintas partes del mundo, de ahí que ya a inicios de 2020 fuera declarada como una «emergencia internacional» por la Organización Mundial de la Salud (OMS) (Lima et al., 2020). Además, puso en evidencia las contradicciones del modelo económico y sociolaboral adoptado, al exhibir la situación de desigualdad social y pobreza, y el consiguiente impacto diferencial sobre los grupos más vulnerables, al igual que las debilidades del sistema privado de seguridad y atención sanitaria (Laster, 2020).

Las consecuencias sociales, económicas y políticas internas y externas son aún imprevisibles para el país. No obstante, el impacto en el desempleo, comparable únicamente con los efectos de la Gran Depresión de la década de 1930, impactará de modo directo sobre la desigualdad social y condiciones de pobreza, ya de por sí incrementadas con la crisis de 2008, que afecta a un amplio sector de la población en riesgo y que entraña una crisis alimentaria ante la caída de los ingresos familiares y el deterioro de la capacidad adquisitiva. Todo ello además se ha enrarecido por la agudización de los conflictos étnico-raciales y las protestas y movilizaciones recientes ante los atropellos y vejaciones infligidos a las minorías afroamericanas y latinas que han sido sistemáticamente excluidas.

Cabe resaltar que la pandemia tiene un componente de clase y étnico-racial. Si bien el virus puede contagiar a cualquier individuo, la probabilidad de ser contagiado, y los efectos que ese contagio pueden tener en la salud y muerte de la persona varían sustancialmente según condiciones sociales, políticas, demográficas y económicas. La desigualdad social constituye un contexto fundamental para 
determinar el modo como cada persona y cada colectivo social sobreviva a la enfermedad, o si incluso mueran enfrentándola (Tai et al., 2020).

Asimismo, no todos pueden mantener por tiempo prolongado medidas de confinamiento y cuidado a la salud ante la necesidad de asegurar sus ingresos; o aislarse y permanecer en sus viviendas en las que no siempre cuentan con las condiciones adecuadas; o, menos aún, decidir acerca de esquemas de trabajo en casa o a distancia. Son muchos factores que propician que sean las comunidades afroamericanas y latinas las más vulnerables y propensas a contagiarse (Solis et al., 2020). En Estados Unidos una parte importante de las actividades de servicio que requieren de la presencia física del trabajador en labores de atención directa a la población son desempeñadas por trabajadores afroamericanos y latinos, que por consiguiente quedan expuestos a los riesgos de contagio.

En ese sentido, los colectivos migrantes conforman una categoría social que, por su condición de vulnerabilidad social, de menor acceso a los sistemas de protección social, aunado a casos de situación de irregularidad migratoria, hacen de ellos sujetos especialmente expuestos a los efectos negativos de la pandemia, no sólo en su salud, sino también en su situación social, económica y migratoria.

Concerniente a la población migrante, su vulnerabilidad frente a la pandemia se manifiesta en tres formas diferentes (Naciones Unidas, 2020). Por un lado, como crisis sanitaria que deriva en una virtual crisis migratoria propiamente tal. Los migrantes, por su misma condición migratoria (agravada en aquellos casos de situación migratoria irregular), están expuestos a situaciones de riesgo y vulnerabilidad frente al virus, así como a las consecuencias de las medidas de restricción y confinamiento impuestas por las autoridades. En segundo lugar, como una crisis de protección. La desprotección social y política, junto a un escenario social y económico totalmente desfavorable, plantea una condición de alta vulnerabilidad que atenta de forma directa a sus condiciones de salud y riesgos de contagio y expansión de la pandemia en sus propias comunidades. En tercer lugar, como una crisis económica y laboral. La pandemia ha provocado una desaceleración en la actividad económica que ya se manifiesta en una importante pérdida de empleos, incremento del desempleo y precarización de los puestos de trabajo; ante dicha situación los migrantes y otras minorías étnicas son particularmente afectados debido a su menor disponibilidad de recursos familiares, sociales e institucionales a los cuales acceder para afrontar la crisis. 
En esta ocasión interesa analizar la vulnerabilidad de los migrantes durante la pandemia desde dos de sus manifestaciones. Por un lado, a partir de los impactos que la crisis económica ha provocado en la situación laboral y ocupacional de los colectivos migrantes en Estados Unidos y, por otro lado, la desigualdad social y étnico-demográfica frente a los impactos de la pandemia en las condiciones de salud, enfermedad y muerte de las poblaciones.

\section{Racialización de la desigualdad social en Estados Unidos. El contexto estructural}

"La raza continúa siendo una fuerza ponderosa que divide a nuestra sociedad» (The New York Times, 10 de enero de 2017). Así se refería Barack Obama en su discurso de despedida como presidente frente al problema del racismo y la xenofobia en Estados Unidos, y lo asumía como uno de los grandes temas pendientes que debieran definir la agenda social y política de ese país. Desde siempre, el racismo y la diferenciación étnica han formado parte de la estructura social y cultural en el país. Diversos autores han estudiado su conformación histórica y sus mecanismos de reproducción y transformación en el tiempo (Myrdal, 1944; Bonilla-Silva, 2002; Omi y Winant, 2015). A lo largo de la historia de Estados Unidos, una parte importante de la desigualdad observada en el empleo, la educación, la salud, el acceso a la vivienda, entre otros, tiene su base en la inequitativa distribución de oportunidades reproducidas con el tiempo, que establecen las funciones y los supuestos lugares que cada individuo debe ocupar en la sociedad estadounidense, generalmente definidos por la raza, el color de piel, la condición migratoria, el origen étnico-nacional, o la clase social.

El asesinato de George Floyd, ciudadano afroamericano, por parte de funcionarios policiales de Minneapolis, MN, y las masivas protestas y manifestaciones que este hecho criminal originó, es el mejor ejemplo de que el racismo, la xenofobia y la discriminación son algunos de los ejes de mayor importancia en la forma de estructuración del conflicto social y político en ese país. El caso de Floyd no es el único, se inserta en una larga serie de actos de racismo y discriminación que, en los últimos años y bajo el amparo del gobierno de Donald Trump, se han venido suscitando en Estados Unidos (Holmes, 2020). Lo relevante es que este caso ha vuelto a poner el tema del racismo en el debate social y político actual de esa nación y en las demás sociedades del mundo desarrollado. 
En Estados Unidos el racismo no sólo se manifiesta como un modo de dominación y discriminación con base en la condición étnico-racial, sino también como un modo de racialización de la desigualdad social y la estructura de clases. Al respecto, los datos referentes a la distribución del ingreso según estratos sociales y grupos étnico-raciales son elocuentes. De acuerdo con estimaciones de 2019 y 2020, 60 por ciento de la población norteamericana es de origen blanco. Sin embargo, ese grupo está sobrerrepresentado en los estratos altos de ingreso, a la vez que subrepresentado en los estratos bajos. Los blancos comprenden 72 por ciento de la población de los estratos con ingresos familiares con más de 200 mil dólares anuales, y 68 por ciento de los de estratos de clase media alta, con ingresos familiares entre 100 mil y 200 mil dólares anuales. Por el contrario, en la población con ingresos por debajo de la línea de pobreza, los blancos sólo representan 41 por ciento del total, proporción que sube a 54 por ciento en el caso de la población de clase media baja (no pobres, pero con ingreso familiar menor a 50 mil dólares anuales), aunque aún por debajo de su promedio nacional (véase cuadro 1).

\section{CUADRO 1}

Composición étnico-racial de la población según estratos de ingreso familiar, Estados Unidos, 2019-2020

\begin{tabular}{lcccccc} 
& Total & Pobres & $\begin{array}{c}\text { Media baja } \\
(50 \text { mil \$) }\end{array}$ & $\begin{array}{c}\text { Media } \\
(\text { hasta } 100 \\
\text { mil \$) }\end{array}$ & $\begin{array}{c}\text { Media alta } \\
\text { (hasta 200 } \\
\text { mil \$) }\end{array}$ & $\begin{array}{c}\text { Alta (más de } \\
\text { 200 mil \$) }\end{array}$ \\
\hline Total & 324544855 & 36319280 & 83947603 & 90131640 & 79203679 & 34952655 \\
Blancos & 194851148 & 15060467 & 45288157 & 54981167 & 54224083 & 25297274 \\
Latinos & 60348722 & 10104679 & 19296485 & 17427196 & 10366195 & 3154169 \\
Afroamericanos & 43984722 & 8490348 & 13986956 & 11228505 & 7709461 & 2569611 \\
Otras minorías & 25370106 & 2663787 & 5376006 & 6494772 & 6903940 & 3931602 \\
\hline Total & $100 \%$ & $100 \%$ & $100 \%$ & $100 \%$ & $100 \%$ & $100 \%$ \\
Blancos & $60 \%$ & $41 \%$ & $54 \%$ & $61 \%$ & $68 \%$ & $72 \%$ \\
Latinos & $19 \%$ & $28 \%$ & $23 \%$ & $19 \%$ & $13 \%$ & $9 \%$ \\
Afroamericanos & $14 \%$ & $23 \%$ & $17 \%$ & $12 \%$ & $10 \%$ & $7 \%$ \\
Otras minorías & $8 \%$ & $7 \%$ & $6 \%$ & $7 \%$ & $9 \%$ & $11 \%$ \\
\hline
\end{tabular}


La distribución de la población blanca contrasta con la forma en que lo hacen las minorías étnico-demográficas. En el caso de la población de origen afroamericano, por ejemplo, aunque sólo representan 14 por ciento del total de los norteamericanos, conforman 23 por ciento de la población en situación de pobreza, a la vez que 17 por ciento de la población de clase media-baja. Asimismo, sólo componen 10 por ciento de la población de clase media alta y 7 por ciento de la clase alta, con ingresos por sobre los 200 mil dólares anuales. La población de origen latino muestra una situación muy similar. Si bien constituyen 19 por ciento de la población norteamericana, representan, no obstante, 28 por ciento de la población en situación de pobreza y 23 por ciento de la clase media-baja, con ingresos inferiores a 50 mil dólares anuales. Por el contrario, configuran sólo 13 por ciento de la población de clase media alta y 9 por ciento de las clases altas.

Estos datos ilustran la dimensión que alcanza la racialización de la desigualdad social, en donde la inserción en los diferentes estratos y clases sociales ya no está directamente determinada sólo y exclusivamente por la posición en la matriz laboral y económico-productiva, sino está mediada por el color de la piel y el origen étnico-migratorio (Canales, 2019). Es el racismo en su máxima expresión sin mediaciones demográficas que lo oculten. Las clases se muestran diferenciadas por color, etnia y origen migratorio. Por lo mismo, la reproducción de la sociedad como un todo, y de su estructura de clases, es racializada y toma forma de acuerdo con la matriz étnico-racial que la conforma. En palabras de Ricciardi (2017:18), en las sociedades avanzadas, como en Estados Unidos, «el racismo no se refiere a la discriminación o al rechazo de un genérico otro, sino más bien, a su incorporación diferencial al interior de las tres figuras colectivas fundamentales [sociedad, pueblo y nación]».

En cierta manera, tal racialización de la desigualdad social comprueba nuestra tesis de que «en la sociedad global la condición de vulnerabilidad social (de minoría social, demográfica y cultural) deja de ser el riesgo de una posible exclusión económica, para convertirse en la condición necesaria para su inclusión», en tanto son constituidos como sujetos subordinados y sometidos a un régimen de desigualdad, explotación y discriminación social (Canales, 2003:68). Asimismo, la pandemia por covid-19 refrenda esa condición estructural de la matriz de la desigualdad social en Estados Unidos. Sus impactos en materia de salud y en las condiciones económicas son de igual modo diferenciados según condición étnico-migratoria y de clase. 


\section{Racialización de la desigualdad social frente a la pandemia por covid-19}

Ya antes de la pandemia Estados Unidos presentaba una situación de creciente inequidad en diversos indicadores de bienestar social y acceso a la salud. Un primer dato que muestra tal situación es la desigual vulnerabilidad de los diferentes grupos étnico-raciales, medida según el grado de acceso al sistema de seguridad social. En el cuadro 2 se aprecia que entre 2019 y 2020 sólo 9 por ciento de la población norteamericana no tenía acceso a ningún sistema de salud y atención sanitaria. Sin embargo, mientras que 6 por ciento de la población de origen blanco se encontraba en situación de vulnerabilidad sanitaria, la proporción se elevó a 10 por ciento en los afroamericanos y a 18 por ciento en los latinos. Estas diferencias ilustran cómo, al igual que con la distribución de los ingresos, la desigualdad social en contraposición a la salud y la enfermedad es también una forma de desigualdad étnico-racial.

\section{CUADRO 2}

Estados Unidos. Desigualdad social étnico-racial frente a la salud y la enfermedad

Total Blancos Latinos Afroamericanos Asiáticos $\begin{gathered}\text { Otras } \\ \text { minorías }\end{gathered}$

\begin{tabular}{lcccccc}
\hline $\begin{array}{l}\text { Población sin acceso a sistema } \\
\text { de salud, 2019-2020(1) }\end{array}$ & $9 \%$ & $6 \%$ & $18 \%$ & $10 \%$ & $7 \%$ & $14 \%$ \\
\hline $\begin{array}{l}\text { Prevalencia de enfermedades, } 2018(2) \\
\text { Diabetes }\end{array}$ & $10.5 \%$ & $8.5 \%$ & $14.3 \%$ & $13.8 \%$ & $11.2 \%$ & $17.3 \%$ \\
Obesidad & $30.4 \%$ & $29.4 \%$ & $34.3 \%$ & $37.0 \%$ & $11.8 \%$ & $41.2 \%$ \\
Hipertensión & $31.8 \%$ & $30.4 \%$ & $30.2 \%$ & $41.7 \%$ & $28.7 \%$ & $37.9 \%$ \\
\hline
\end{tabular}

Fuente: (1) estimaciones propias con base en microdatos de IPUMS de la Current Population Survey, suplemento socioeconómico anual de 2019 y 2020 (Flood et al., 2020);

(2) estimaciones propias con base en «National Health Interview Survey», 2018.

Junto a esta desigualdad en la protección en cuanto al acceso a los sistemas de salud, también existe una diferente prevalencia de enfermedades y padecimientos crónicos que, como la obesidad, hipertensión y la diabetes, constituyen además marcos de mayor vulnerabilidad a otras enfermedades y riesgos a la salud. De acuerdo con los resultados de la Encuesta Nacional de Salud de los Estados Unidos de 2018, las minorías étnico-raciales presentan sistemáticamente 
mayor prevalencia de ese tipo de enfermedades. Muestra de ello es que 8.5 por ciento de la población de origen blanco no latino padece de diabetes, en contraste con 14 por ciento aproximadamente de latinos y afroamericanos. Asimismo, la obesidad, que se ha convertido en una condición de riesgo de salud a escala mundial, en Estados Unidos no afecta a todos por igual; mientras 29.4 por ciento de blancos padece de obesidad, con un índice de masa corporal superior a 30 , esta situación afecta a 34.3 por ciento de latinos y a 37 por ciento de afroamericanos. Concerniente a la hipertensión, otro mal de nuestra sociedad contemporánea, también es desigual según la condición étnico-racial, puesto que 30.4 por ciento de blancos no latinos tiene hipertensión, en comparación con casi 42 por ciento de afroamericanos.

Estos datos refieren a una racialización de la desigualdad social frente a los procesos de salud, enfermedad y muerte de la población. En ese contexto, la actual crisis sanitaria generada por la covid-19 ha exacerbado la racialización del contagio entre grupos afroamericanos y latinos, consecuencia de la disparidad social que permea dicha sociedad. Si bien en principio cualquier persona es susceptible a ser contagiada, ni la exposición al riesgo ni las maneras de combatirlo resultan iguales en el conjunto de la población. En Estados Unidos es evidente que la desigualdad social concerniente a la salud adopta una forma racializada, en la cual la desigualdad étnica constituye la forma en que se expresa la desigualdad social y de clases. De ahí que la covid-19 haya afectado en mayor medida a la población afroamericana y latina, con un número superior de contagios, hospitalizaciones y muertes, resultado de las profundas condiciones de desigualdad social, étnicas, de raza y clase en el país.

Al 14 de noviembre se habían registrado en Estados Unidos 10.7 millones de casos confirmados de covid-19, lo que representa una incidencia de 32.4 casos por cada mil habitantes. Sería de esperar que ese volumen e incidencia de contagios se distribuyera proporcionalmente de acuerdo con el tamaño demográfico de cada grupo étnico-racial. No obstante, los datos muestran que, aunque el virus no reconoce etnias ni razas, éstas enfrentan la epidemia en desiguales condiciones sociales y sanitarias. Por un lado, la población blanca no latina, que compone 60 por ciento de la población, sólo concentra 49 por ciento de los casos por covid-19. Por el contrario, los afroamericanos y los latinos, que representan 12 y 19 por ciento de la población, concentran 16 y 26 por ciento de los casos (véase cuadro 3). Este desajuste en la distribución de los contagios respecto a la distribución de la población se refleja en una desigual incidencia de la 
enfermedad en cada grupo étnico-racial. Así, en cuanto a la población blanca, 26 de cada mil personas se han contagiado, mientras que la tasa se incrementa a 37.5 contagios por cada mil personas en la población afroamericana, y a 45.9 en la población de origen latino.

\section{CUADRO 3}

Tasas de incidencia de contagios, de mortalidad y de hospitalizaciones por covid-19 en Estados Unidos según grupo étnico-racial. Datos al 14 de noviembre de 2020

\begin{tabular}{lcccccc} 
& Total & Blancos & Latinos & Afroamericanos & Asiáticos & $\begin{array}{c}\text { Otras } \\
\text { minorías }\end{array}$ \\
\hline $\begin{array}{l}\text { Casos de contagios (\%) } \\
\begin{array}{l}\text { Tasa de incidencia de contagios } \\
\text { (por mil habitantes) }\end{array}\end{array}$ & $100 \%$ & $49 \%$ & $26 \%$ & $16 \%$ & $3 \%$ & $6 \%$ \\
$\begin{array}{l}\text { Tasa de hospitalización } \\
\text { (por 100 mil habitantes) }\end{array}$ & 217.2 & 123.2 & 333.5 & 354.0 & 120.6 & 393.0 \\
$\begin{array}{l}\text { Tasa de mortalidad ajustada } \\
\text { por edad } \\
\text { (por 100 mil habitantes) }\end{array}$ & 69.0 & 48.4 & 141.7 & 142.7 & 59.0 & 111.6 \\
$\begin{array}{l}\text { Incidencia de covid-19 } \\
\text { en mortalidad general }\end{array}$ & $9.1 \%$ & $6.7 \%$ & $20.6 \%$ & $13.6 \%$ & $13.3 \%$ & $12.0 \%$ \\
\hline
\end{tabular}

Fuente: estimaciones propias con base en Centers for Disease Control and Prevention, 2020.

La desigualdad étnico-racial no sólo refiere la incidencia de la enfermedad sino también, y fundamentalmente, sus efectos referentes a las condiciones de salud y muerte que afectan a cada grupo social. Por un lado, la tasa de hospitalización es sustancialmente mayor en las minorías étnicas (en la población latina la cifra asciende a 333.5 hospitalizados por cada 100 mil habitantes y en la población afroamericana a 354), en comparación con la población blanca, cuya tasa de hospitalización comprende 123.2 personas por cada 100 mil habitantes. Asimismo, la mortalidad por covid-19 es significativamente desigual según el origen étnico-racial, pues la tasa de mortalidad de los blancos es de 48.4 muertes por cada 100 mil habitantes, en los latinos la tasa se eleva a 141.7 muertes y a 142.7 muertes en los afroamericanos (tasas ajustadas por estructura etaria).

Para dimensionar el impacto global que tienen las desigualdades étnicoraciales sobre la condición de salud, enfermedad y muerte de las poblaciones, se estima el peso relativo de la covid-19 como causa de muerte en cada grupo étnico-demográfico. Esto nos da una idea aproximada de cuánto ha contribuido la pandemia a incrementar la mortalidad general en cada caso, al profundizar 
de ese modo las diferencias ya existentes en la mortalidad según la condición étnico-demográfica de la población.

$\mathrm{Al}$ respecto, los datos son elocuentes. Concerniente a los blancos no latinos, al 14 de noviembre la covid-19 habría contribuido con 6.7 por ciento del total de defunciones, situación que contrasta con lo que ocurre entre las diferentes minorías étnico-raciales. En los afroamericanos, por ejemplo, a la misma fecha la covid-19 fue responsable de casi 14 por ciento de la mortalidad general, proporción que se elevó a casi 21 por ciento en la población de origen latino. Estas diferencias no son menores y respaldan lo ya señalado: la covid-19 ha profundizado la desigualdad étnico-racial en el ámbito de la salud y la muerte en Estados Unidos.

\section{Impactos económicos y laborales de la pandemia}

La pandemia por covid-19 no sólo ha tenido impactos en las condiciones de salud y muerte de la población, sino también en sus condiciones socioeconómicas y bienestar. Las diversas medidas implementadas para combatir la pandemia han tenido efectos directos en la dinámica económica y productiva. El confinamiento, las cuarentenas obligatorias de amplios territorios, el cese de actividades no esenciales, la reducción y limitación a la movilidad de las personas que afecta a trabajadores y a consumidores, el cierre temporal de centros comerciales, centros productivos, actividades públicas de todo tipo, entre otras medidas, han implicado tanto un freno a la demanda y el consumo, como a la oferta y la producción.

En efecto, en la gráfica 1 se observan los efectos de la pandemia por covid-19 en la dinámica de la economía norteamericana. Hasta el cuarto trimestre de 2019, el producto interno bruto (PIB) mostraba un crecimiento estable y sostenido, a un ritmo promedio de 0.55 por ciento cada trimestre, que implicaba un promedio anual de casi 2.2 por ciento. Sin embargo, ya en el primer trimestre del 2020 el PIB sufrió una primera caída de 1.3 por ciento en comparación con el último trimestre de 2019; y en el siguiente trimestre experimentó los mayores efectos de la crisis generada por la pandemia, al caer 9 por ciento respecto al ya alicaído primer trimestre. Si bien en el tercer trimestre muestra una importante recuperación con un crecimiento de 7.4 por ciento, únicamente se recuperó el nivel que se tuvo durante el primer trimestre de 2018, más de dos años y medio atrás. De hecho, el valor del PIB al tercer trimestre de 2020 es aún 2.7 por ciento inferior al que se tenía en promedio en 2019. 


\section{GRÁFICA 1}

Estados Unidos, 2018-2020. Producto Interno Bruto

por trimestre (miles de millones de dólares, a precios de 2012)

$\$ 20,000$

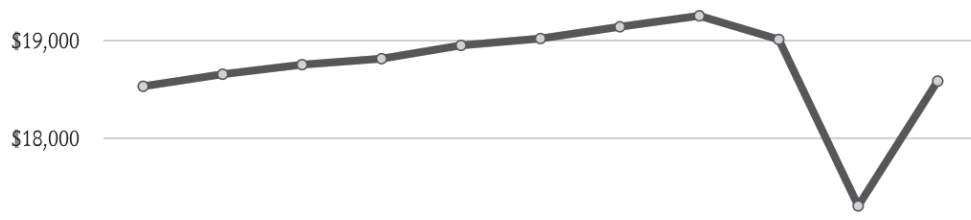

$\$ 17,000$

$\$ 16,000$

2018

2019

2020

Fuente: U.S. Bureau of Economic Analysis, 2020.

El impacto de la caída del PIB y la actividad económica fue palpable inmediatamente en el volumen de empleo y la tasa de desocupación. El total de puestos de trabajo ocupados, que venía creciendo lenta pero sistemáticamente en 2019, se redujo de 158.4 millones en febrero de 2020 a 133.7 millones en abril del mismo año. Esto es, en dos meses la ocupación se redujo en 15.6 por ciento, con lo que se perdieron casi 25 millones de puestos de trabajo. Aunque en los meses siguientes ha habido una recuperación, todavía no se ha retomado el nivel que se tenía en 2019, con 148.9 millones de empleos, cifra que es aún 6 por ciento inferior al promedio del año previo (véase gráfica 2).

\section{Gráfica 2}

Volumen de ocupados y tasa de desempleo, Estados Unidos, enero 2019-septiembre 2020

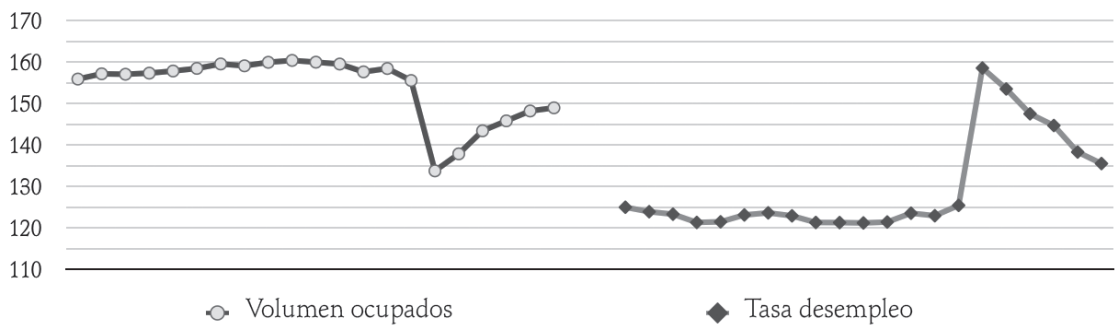

$18.0 \%$

$13.5 \%$

$9.0 \%$

$4.5 \%$

$0.0 \%$

Fuente: estimaciones propias con base en microdatos de IPUMS de la Current Population Survey, Basic, de enero 2019 a septiembre de 2020 (Flood et al., 2020). 
Complementariamente, la caída del empleo incrementó la tasa de desempleo, que pasó de 3.9 por ciento en febrero de 2020 a 14.6 por ciento en abril del mismo año, es decir, casi se cuadruplicó en dos meses. Al igual que con la ocupación y los puestos de trabajo, la tasa de desempleo se redujo en los meses siguientes, pero su recuperación es lenta y no exenta, de modo tal que en septiembre de 2020 se mantuvo en 7.6 por ciento, más del doble del que se tenía a comienzos de año, antes de que se declarase la pandemia por covid-19.

Al descomponer las tendencias del empleo y desempleo según condición étnico-migratoria de los trabajadores, se observan diferencias que reflejan la racialización de la desigualdad en el mercado laboral. Un primer aspecto a tomar en cuenta es que la pérdida de empleos no afecta en la misma medida a las minorías étnicas y migratorias y a la población blanca. De acuerdo a la información que reporta la Encuesta Continua de Población (CPS mensual), a partir de marzo, cuando inicia la pandemia y las medidas de confinamiento y cese de actividades no esenciales, se da una sustancial pérdida de puestos de trabajo. En la población blanca no latina la caída del empleo fue de 14.3 por ciento con relación al volumen que en promedio se tenía en 2019. Por el contrario, en los trabajadores afroamericanos la caída del empleo fue de 16.8 por ciento, y de 19.3 por ciento en la población de origen latino (véase gráfica 3).

\section{GRÁFICA 3}

Estados Unidos, enero 2019 a septiembre 2020. Índice de ocupación según principales grupos étnicos-demográficos $(2019=100)$

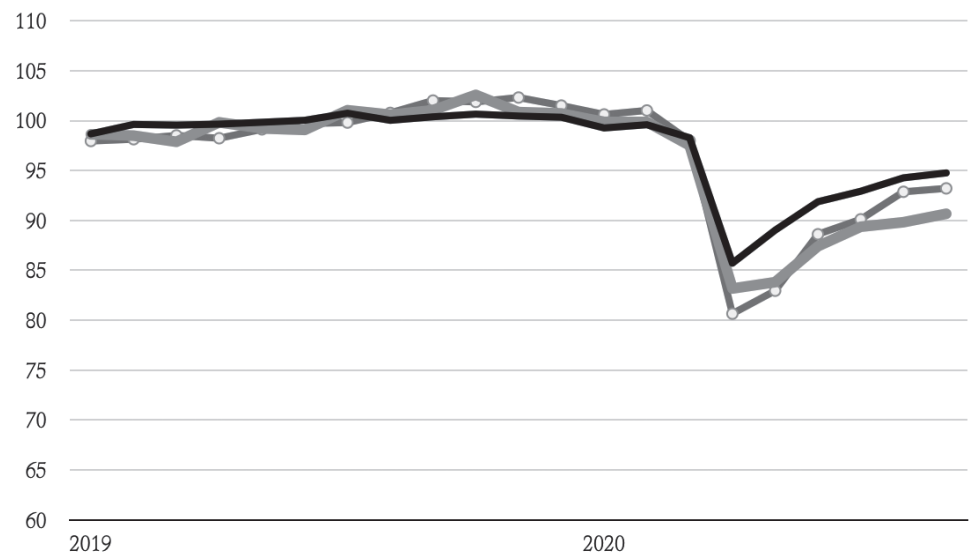

Fuente: estimaciones propias con base en microdatos de IPUMS de la Current Population Survey, Basic, de enero 2019 a septiembre de 2020 (Flood et al., 2020). 
Durante los meses siguientes comenzó una recuperación en el nivel de empleo, pero se presentó de manera desigual pues favoreció a la población blanca no latina, cuyo nivel de empleo en septiembre de 2020 sólo fue 5 por ciento inferior al promedio de 2019. En contraste, el nivel de empleo de los latinos se mantuvo por sobre 7 por ciento del obtenido en 2019, y el de los afroamericanos es casi 10 por ciento inferior al mismo periodo.

La pérdida de empleos se refleja directamente en el incremento en la tasa de desempleo, la cual reproduce vis a vis las desigualdades étnico-raciales ya señaladas. La tasa de desempleo de los trabajadores blancos no latinos pasa de 3 por ciento en promedio en 2019 a 12.9 por ciento en abril de 2020, y posteriormente a 6.1 por ciento en septiembre del mismo año; una mejoría importante que sin embargo se mantiene muy por encima del promedio histórico para ese grupo étnico (véase gráfico 4).

Para los trabajadores de origen afroamericano, la crisis económica y laboral generada por la pandemia hizo que la tasa de desempleo pasara de 6.2 por ciento que se tenía en 2019 a 16.7 por ciento en abril de 2020, casi cuatro puntos porcentuales por encima de la experimentada por la mayoría blanca. La recuperación experimentada en los meses siguientes fue más lenta y gradual, de tal modo que en septiembre de 2020 todavía se mantenía una tasa de desempleo de 11.4 por ciento, cifra que supera a la de los demás grupos étnico-raciales.

Por último, para los trabajadores latinos ocurrió algo similar. Por efecto de la crisis económica asociada a la pandemia, su tasa de desempleo prácticamente se cuadruplicó, pasando de un promedio de 4.3 por ciento en 2019 a 18.7 por ciento en abril de 2020. Este grupo étnico fue el más perjudicado en materia de desempleo. Su recuperación fue más pronta que la de los trabajadores afroamericanos, por lo que en septiembre la tasa de desempleo se había reducido a 10 por ciento, por debajo de la de aquel grupo, pero muy por encima de su nivel histórico y superior a la de la población blanca no latina. 


\section{GRÁFICA 4}

Estados Unidos, enero 2019 a septiembre 2020. Tasa de desempleo según principales grupos étnicos-demográficos (\%)

$20 \%$

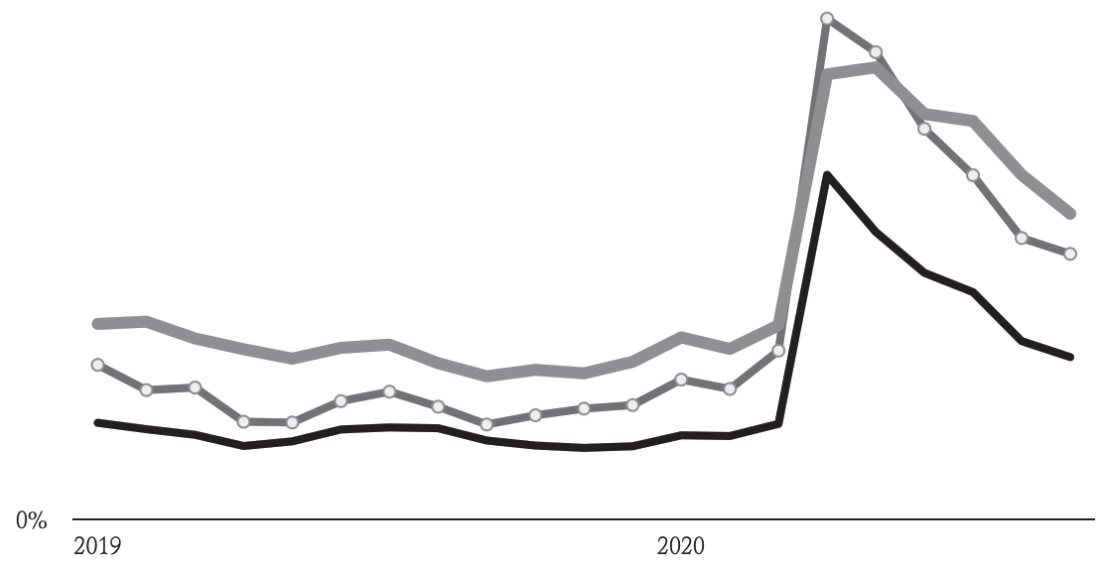

Fuente: estimaciones propias con base en microdatos de IPUMS de la Current Population Survey, Basic, de enero 2019 a septiembre de 2020 (Flood et al., 2020).

\section{Conclusiones}

Desde finales de marzo Estados Unidos se convirtió en el país con mayor incidencia de casos por covid-19 a escala mundial, posición que mantiene hasta el día de hoy (15 de noviembre), cuando el volumen de contagios superó los 11.3 millones de casos, muy por encima de los 8.45 millones reportados por India, los 5.86 millones de Brasil y los casi 2 millones de Francia y Rusia. Este volumen hace que sólo en Estados Unidos se concentre un quinto del total de casos contagiados por covid-19 en el mundo. De igual forma, cuando ya se ha pasado la barrera de los 1.3 millones de defunciones por dicha enfermedad, destaca el hecho de que Estados Unidos reporte 251 mil de esas defunciones, lo que representa 18 por ciento del total. A la gravedad de la situación que ilustran tales cifras cabe añadir un hecho no menor: la gran desigualdad social y étnico-racial que le subyace.

Como sostiene Therborn, «la desigualdad social mata» (2016:15), y en este caso, los datos sobre incidencia y mortalidad por covid-19 muestran que en Estados Unidos su principal instrumento es el racismo, en tanto modo de estructuración 
de los desiguales impactos de la pandemia sobre la salud, la enfermedad y la muerte de los diferentes grupos étnico-raciales que conforman la población norteamericana.

Los datos presentados son elocuentes y evidencian la racialización de la desigualdad frente a la incidencia de esta enfermedad. Aun cuando el virus no reconoce condición étnica ni racial, ello no implica que la desigualdad social que prevalece no genere condiciones adversas que afectan preponderantemente a las minorías étnicas. La racialización de la desigualdad social se manifiesta en las grandes brechas étnico-raciales en cuanto a los efectos e incidencia de la pandemia, y hace que los mayores efectos negativos los sufran las minorías étnicas. En ellas se concentra el mayor efecto en la salud de la población, así como el mayor volumen de defunciones.

Asimismo, la desigualdad étnico-racial también aflora cuando se analizan y comparan los impactos de la pandemia sobre la dinámica económica y del mercado laboral. No es casual que sean las minorías étnico-raciales, una vez más, las que están más expuestas a la precarización de trabajos, reducción de salarios, nuevas formas de explotación laboral, pérdida de empleos y el drama del desempleo. Aunque la crisis afecta a todos, no lo hace por igual, a la vez que la incipiente recuperación económica y del empleo en meses recientes tampoco favorece a todos del mismo modo. Son las mayorías étnico-raciales (blancos no latinos) las que suelen ser menos perjudicadas por los momentos de crisis económica y sanitaria, las más favorecidas en los momentos de recuperación económica porque cuentan con mayores niveles de protección social e institucional para enfrentar los efectos de la pandemia.

\section{Referencias}

Bonilla Silva, Eduardo (2002), "We are all Americans! The Latin Americanization of racial stratification in the USA», Race and Society, 5, pp. 3-16.

Canales, Alejandro I. (2003), «Demografía de la desigualdad. El discurso de la población en la era de la globalización», en Alejandro I. Canales y S. Lerner (coords.), Desafíos teóricometodológicos en los estudios de población en el inicio del milenio, México, Sociedad Mexicana de Demografía/Universidad de Guadalajara/El Colegio de México, pp. 43-86. (2019), Migration, reproduction and society. Economic and demographic dilemmas in global capitalism, Leiden, Boston, Brill Publisher. 
Centers for Disease Control and Prevention (CDC) (2020), "Coronavirus disease 2019 (covid-19)", en https://www.cdc.gov/coronavirus/2019-ncov/cases-updates/ index.html

Flood, Sarah, Miriam King, Renae Rodgers, Steven Ruggles y J. Robert Warren (2020), Integrated Public Use Microdata Series, Current Population Survey: Version 8.0 [dataset], Minneapolis, MN, IPUMS, DOI: https://doi.org/10.18128/D030.V8.0

Holmes IV, O. (2020), «Police brutality and four other ways racism kills Black people», Equality, Diversity and Inclusion, 39(7), pp. 803-809. DOI: https://doi.org/10.1108/ EDI-06-2020-0151

Laster Pirtle, Whitney N. (2020), «Racial capitalism: a fundamental cause of novel coronavirus (covid-19). Pandemic inequities in the United States», Health Education \& Behavior 2020, 47(4), pp.504-508. DOI: https://doi.org/10.1177/1090198120922942

Lima, Nísia Trindade, Paulo Marchiori Buss \& Rômulo Paes-Sousa (2020), «A pandemia de covid-19: uma crise sanitária e humanitária», Cad. Saúde Pública 2020, 36(7), e00177020.

Myrdal, Gunnar (1944), An American dilemma. The Negro problem and modern democracy, Nueva York y Londres, Harper and Brothers Publishers.

144

Naciones Unidas (2020), Documento de politicas del Secretario General sobre la covid-19 y las personas en movimiento, Nueva York, Naciones Unidas, 20-07486X (S).

National Health Interview Survey (2018), National Health Interview Survey, 2018 Data Release, Center for Disease Control and Prevention, National Center for Health Statistics, United States.

Omi, Michael y Howard Winant (2015), Racial formation in the United States, Nueva York, Routledge/Taylor \& Francis Group.

Ricciardi, Maurizio (2017), «Migrantes, poder y capital. Acerca de la teoría política de las migraciones», en Jorge Olvera García, Norma Baca Tavira, Maurizio Riccardi y Susan Sanhueza Henríquez (coords.), Migración y trabajo en el capitalismo global, México, Universidad Autónoma del Estado de Morelos/Universidad de Bologna/ Universidad Católica del Maule/GEDISA, pp. 15-37.

Solis, Jamie, Carlos Franco-Paredes, Andrés F. Henao-Martínez, Martin Krsaky Shanta M. Zimmer (2020), «Structural vulnerability in the U.S. revealed in three waves of covid-19», The American Journal of Tropical Medicine and Hygiene, 103(1), pp. 25-27, DOI: https://doi.org/10.4269/ajtmh.20-0391

Tai, Don Bambino Geno; Aditya Shah; Chyke A. Doubeni, Irene G. Sia y Mark L. Wieland (2020), «The disproportionate impact of covid-19 on racial and ethnic minorities in 
the United States», Clinical Infectious Diseases, ciaa815. DOI: https://doi.org/10.1093/ $\mathrm{cid} / \mathrm{ciaa} 815$

The New York Times (10 de enero de 2017), President Obama's farewell address: full video and text, en https://www.nytimes.com/2017/01/10/us/politics/obama-farewell-address -speech.html? $\mathrm{r}=0$

Therborn, Göran (2016), Los campos de exterminio de la desigualdad, México, Fondo de Cultura Económica.

U.S. Bureau of Economic Analysis (2020), «Table 1.1.6. Real gross domestic product, chained dollars», en https://apps.bea.gov/iTable/iTable.cfm?reqid=19\&step=2\#r eqid=19\&step $=2 \&$ isuri $=1 \& 1921=$ survey 